\title{
Performance and analysis for improvement of power quality and voltage sag mitigation
}

\author{
K.SIVA PRASAD, N.G.V.Satya Kumar, Y.Praveen Kumar Reddy, P.Nagarjuna, G.Shobha \\ Asst.Professor, C.B.I.T, Proddatur, A.P, India
}

\begin{abstract}
Aiming further to reduce its switching losses, an appropriate discontinuous modulation scheme is proposed and studied here in detail to doubly ensure that maxi-mal reduction of commutations is achieved. With an appropriately designed control scheme had incorporated with nine-switch converter is shown to favorably raise the overall power quality and voltage mitigation hence justifying its role as a power conditioner at a reduced semiconductor cost. A nineswitch power converter having two sets of out-put terminals was recently proposed in addition of the traditional backto-back power converter that uses 12 switches in total. The nine-switch converter had already been proven to have certain advantages, in addition to its component saving topological features. Despite these advantages, the nine-switch converter has so requiring an oversized dc-link capacitor, limited amplitude sharing, and constrained phase shift between its two sets of output terminals. Instead of accepting these tradeoffs as limitations, a nine-switch power conditioner is proposed here that virtually "converts" most of these topological shortfalls are overcome into interesting performance advantages.
\end{abstract}

Keywords: voltage sag, mitigation, pulse-width modulation, nine-switch converter, power conditioner, power quality.

\section{INTRODUCTION}

Since in most of the applications power system networks would require the power converters to be connected in series [1] or shunt [2], depending on the operating scenarios under consideration. In addition, they need to be programmed with voltage, current, and/or power regulation schemes so that they can smoothly compensate for harmonics, reactive power flow, unbalance, and voltage variations. For even more stringent regulation of supply quality, both a shunt and a series converter are added with one of them tasked to perform voltage regulation, while the other performs current regulation.

Almost always, these two converters are connected in a back-to-back configuration [3-5], using 12 switches in total and sharing a common dc-link capacitor, as reflected by the configuration drawn in Fig. 1(a). Where available, a microsource can also be inserted to the common dc link, if the intention is to provide for distributed generation in a microgrid [6], without significantly impacting on the long proven proper functioning of the back-to-back configuration. Even though facing no major operating concerns at present, improvements through topological modification or replacement of the back-to-back configuration to reduce its losses, compo-nent count, and complexity would still be favored, if there is no or only slight expected tradeoff in performance. A classical alternative that can immediately be brought out for consideration is the direct or indirect matrix converter, where 18 switches are used in total. That represents six switches more than the back-to-back configuration, but has the advantage of removing the intermediate electrolytic capacitor for compactness and lifespan extension If the heavy switch count is still of concern, those indirect sparse matrix converters proposed in [7], [8] can be considered, where the minimum switch count attain-able is nine, but at the expense of supporting only unidirectional power flow.. Neither storage capacitor no $\mathrm{dc}$ micro source is again needed, which thus renders the

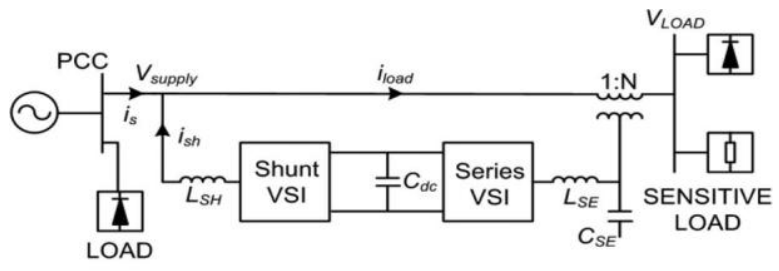

(a)

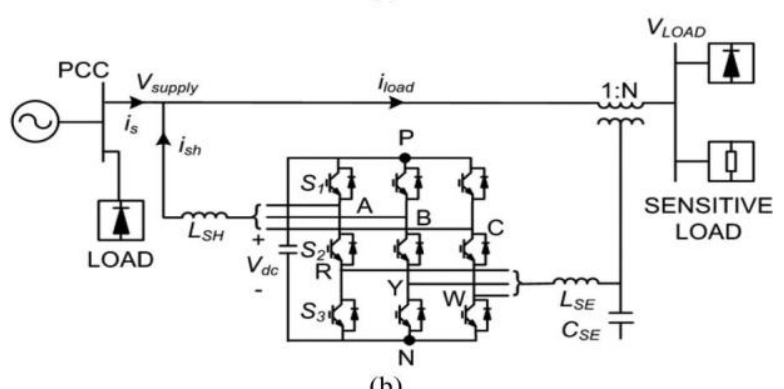

(b)

Fig. 1. (a) Back-to-back and (b) nine-switch power conditioners.

normal and sparse matrix converters as not the preferred choice, if ride-through is a requirement. Matrix converters are also not preferred, if volt-age buck and boost operations are both needed for a specified direction of power flow. More outstandingly a much larger DC link capacitance and voltage need to be continuing in order to generate the same ac voltage amplitudes as for the back to back converter. Unnecessary to say, the superior DC link voltage would exaggerate the semiconductor switches gratuitously and capacity to some extent overshadow the saving of three semiconductor switches made probable by the nine switch topology. The follow up topological extensions can consequently be found in where a Z-source network and substitute modulation schemes are commence that they did not fully address those dangerous limitations faced by the nine switch converter and not its conventional back to back counterpart. 
For tying two AC systems collectively, Enrique Ledezma, Brendan McGrath, Alfredo Munoz, was introduces two B4 converters are desirable with their split DC link shared. The total number of switches needed is thus 8 , which almost certainly is the minimum attainable for crossing point two ac systems.

The ensuing ac-dc-ac converter is supposed to after that be more correctly referred to as the B8 converter that uses four switches per phase. The B8 converter is, conversely known to tolerate from large DC link voltage variation, except both systems are of the same frequency and synchronized so that no fundamental current flows from side to side the DC link. That positively is a restriction in addition to the lower ac voltage that can be by each B4 converter from its given DC link voltage.

Presenting a better reduced semiconductor alternative for high quality series-shunt compensation, this paper proposes a single-stage integrated nine-switch power conditioner, whose circuit connection is shown in Fig. 1(b). As its name roughly inferred, the proposed conditioner uses a nine-switch converter with two sets of output terminals, instead of the usual 12 switch back-toback converter. The nine-switch converter was earlier proposed in [12] and [13] at about the same time, and was recommended for dual motor drives [14], rectifier-inverter systems, and uninterruptible power supplies [15]. Despite functioning as intended, these applications are burdened by the limited phase shift and strict amplitude sharing enforced between the two terminal sets of the nine-switch converter. More importantly, a much larger dc-link capacitance and volt-age need to be maintained, in order to produce the same ac voltage amplitudes as for the back-toback converter. Needless to say, the larger dc-link voltage would overstress the semi-conductor switches unnecessarily, and might to some extent overshadow the saving of three semiconductor switches made possible by the nine-switch topology. The attractiveness of the nineswitch converter, if indeed any, is therefore not yet fully brought out by those existing applications discussed in[13]-[15]. Although follow-up topological extensions can subsequently be found in [16], where a Z-source network and alternative modulation schemes are introduced, they did not fully address those critical limitations faced by the nine-switch converter, and not its traditional back-to-back counterpart.

Investigating further by taking a closer view at those existing applications described earlier, a general note observed is that they commonly use the nine-switch converter to replace two shunt converters connected backto-back. Such replacement will limit the full functionalities of the nine-switch converter, as explained in Section II. In the same section, an alternative concept is discussed, where the nine-switch converter is chosen to replace a shunt and a series converter found in an integrated power conditioner, instead of two shunt converters. Underlying operating principles are discussed comprehensively to demonstrate how such "series-shunt" replacement can bring forth the full advantages of the nine-switch converter, while yet avoiding those limitations faced by existing applications. Details explaining smooth transitions between normal and sag operating modes are also provided to clarify that the more restricted nineswitch converter will not underperform the more independent back-to-back converter even for sag mitigation. Section III then proceeds to compare the ratings and losses of the back-to-back and nine-switch conditioners, before an appropriate, the grid currents drawn from the utility are then sinusoidal, having only fundamental component. In synchronism, the second set of outputs is controlled to compensate for any detected grid voltage harmonics and unbalance, so that only a set of balanced three-phase voltages appears across the loads under normal operating conditions [17]. During voltage sags, the second set of control schemes also has the ability to continuously keep the load voltages within tolerable range.

\section{SYSTEM DESCRIPTION AND OPERATING PRINCIPLE}

\section{A. Back-to-Back Converter}

Fig. 1(a) shows the per-phase representation of the common back-to-back unified power quality conditioner (UPQC), where a shunt converter is connected in parallel at the point-of-common-coupling (PCC), and a series converter is connected in series with the distribution feeder through an isolation trans-former. The shunt converter is usually controlled to compensate for load harmonics, reactive power flow, and unbalance, so that a sinusoidal fundamental current is always drawn from the utility grid, regardless of the extent of load nonlinearity. Complementing, the series converter is controlled to block grid harmonics, so that a set of three-phase fundamental voltages always appears across the load terminals [18].

\section{TABLE I}

\section{SWITCH STATES AND OUTPUT VOLTAGES PER} PHASE

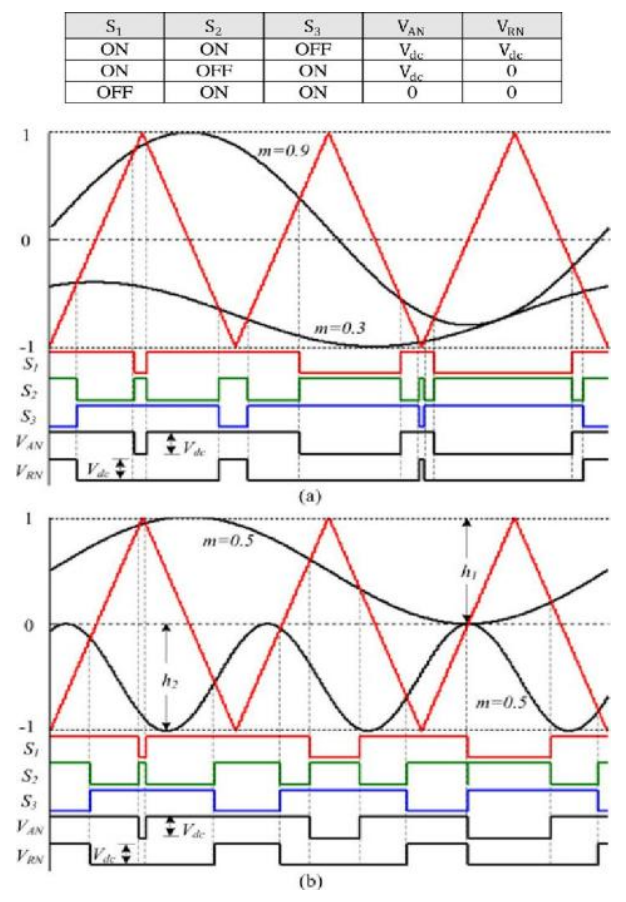

Fig. 2. Arrangements of references having (a) the same frequency but different amplitudes, and (b) different frequencies but the same amplitude 


\section{B. Nine-Switch Converter Operating Principles and Existing Constraints}

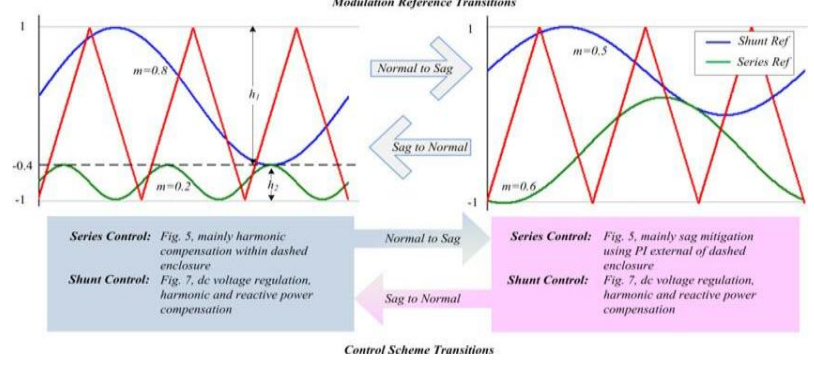

Fig. 3. Transitions of modulating references and control schemes between normal (left) and sag mitigation (right) modes.

As illustrated in Fig. 1(b), the nine-switch converter is formed by tying three semiconductor switches per phase, giving a total of nine for all three phases. The nine switches are powered by a common dc link, which can either be a microsource or a capacitor depending on the system requirements under consideration. Like most reduced component topologies, the nine-switch converter faces limitations imposed on its assumable switching states, unlike the fully decoupled back-to-back converter that uses 12 switches switching states can conveniently be found in Table I, from which, it is clear that the nineswitch converter can only connect its two output terminals per phase to either $V_{\mathrm{dc}}$ or $0 \mathrm{~V}$, or its upper terminal to the upper dc rail $P$ and lower terminal to the lower dc rail $N$. The last combination of connecting its upper terminal to $N$ and lower terminal to $P$ is not realizable, hence constituting the first limitation faced by the nine-switch converter. That limitation is nonetheless not practically detrimental, and can be resolved by coordinating the two modulating references per phase, so that the reference for the upper terminal is always placed above that of the lower terminal, as per the two diagrams drawn in Fig. 2. Imposing this basic rule of thumb on reference placement then results in those gating signals drawn in Fig. 2 for the three switches of $S_{1}, S_{2}$, and $S_{3}$ per phase. Equations for producing them can also be explicitly stated as where $\bigoplus$ is the logical XOR operator. Signals obtained from (1), when applied to the nine-switch converter, then lead to those output voltage transitional diagrams drawn in Fig. 2 for representing $V_{A}{ }_{N}$ and $V_{R}{ }_{N}$ per phase. Together, these voltage transitions show that the forbidden state of $V_{A N}=$ $0 \mathrm{~V}$ and $V_{R N}=V_{\mathrm{dc}} \quad$ is effectively blocked off. The blocking is, how- ever, attained at the incurrence of additional constraints limiting the reference amplitudes and phase shift. These limitations are especially prominent for references having sizable amplitudes and/or different frequencies, as exemplified by the illustrative cases shown in Fig. 2(a) and (b). In particular, Fig. 2(a) shows two references of common frequency limited in their phase dis-placement, while Fig. 2(b) shows two references of different frequencies limited to a maximum modulation ratio of 0.5 each, extendible by 1.15 times if triplen offset is added, in order to avoid crossover. The limited phaseshift constraint, associated with references of the same frequency and combined modula-tion ratio of greater than 1.15 with triple-n offset added (=1.2 in Fig. 2(a) as an example), has recently been shown to adapt well with online uninterruptible power supplies [15], which indeed is a neat and intelligent application of the nine-switch converter. This, however, is only a single application, which by itself is not enough to bring forward the full potential of the nine-switch converter.

Considering now the second limitation detailed in Fig. 2(b), a helpful example for explaining it is the nine-switch dual drive system proposed in [13], where references used for modulation can have different operating frequencies. These references are for the two output terminal sets of the nine-switch converter, tied to separate motors operating at approximately the same rated voltage but at different frequencies. Such motor operating criteria would force the references to share the common car-rier range equally, like that drawn in Fig. 2(b). The maximum modulation ratio allowed is therefore $0.5 \times 1.15$ per reference.

Judging from these examples, the general impression formed is that the nine-switch converter is not too attractive, since its semiconductor saving advantage is easily shadowed by trade-offs, especially for cases of different terminal frequencies. Such unattractiveness is however not universal, but noted here to link only with those existing applications reported to date, where the nine-switch converter is used to replace two shuntconnected converters. References demanded by these shunt converters are usually both sizable, inferring that the carrier band must be shared equally between them, and hence giving rise to those tradeoffs identified earlier.

Therefore, instead of "shunt-shunt" replacement, it is recommended here that the nine-switch converter should more appropriately be used for replacing a series and a shunt converter like those found in a power quality conditioner or any other "series-shunt" topological applications. Explanation for justifying that recommendation is provided in Section II-C with all relevant advantages and residual tradeoffs identified.

\section{Proposed Nine-Switch Power Conditioner}

Under normal operating conditions, the output voltage amplitude of the shunt converter is comparatively much larger than the voltage drop introduced by the series converter along the distribution feeder. That indirectly means the modulating ref-erence needed by the shunt converter is much larger than that associated with the series converter, which might simply consist of only the inverse harmonic components for grid voltage compensating purposes. Drawing these details in the carrier range would then result in a much wider vertical range $h_{1}$ in the left diagram of Fig. 3 for controlling the upper shunt terminal, and a narrower $h_{2}$ for controlling the lower series terminal $\left(h_{1} h_{2}\right)$. Other operating details like logical equations used for gen-erating gating signals for the three switches per phase would remain unchanged, as per (1).

For $h_{2}$, a comment raised here is that it can be set to zero, if an ideal grid with no distortion and rated sinusoidal voltage is considered. In that case, the lowest three switches, labeled as $S_{3}$ for each phase in Fig. 1(b), should always be kept ON to short out the series coupling 
transformer, and to avoid unnec-essary switching losses. If desired, the series transformer can also be bypassed at the grid side to remove unwanted leakage voltage drop without affecting the compensating ability of the shunt converter. Tailored operation with an ideal grid is therefore possible, as described, but for modern grids with abundant distributed nonlinear loads, voltage distortion is relatively com-mon, since any amount of harmonic load current flowing through a finite line or transformer impedance would have caused volt-age at the PCC to be distorted. Series harmonic compensation of the grid or PCC voltage is therefore technically needed, and hence included here for discussion, if a smoother load voltage is demanded.

Referring back to the $h_{1}$ and $h_{2}$ carrier band division shown in the left illustration of Fig. 3, it would still need a higher dc-link voltage as a tradeoff in the UPQC, but the increase is much reduced, and definitely not anywhere close to doubling. Quoting [17] as an example, where a modulation ratio of the series converter can be as low as $0.05 \times 1.15$ with triplen off-set included, the increase in dc-link voltage is merely about $5 \%$, before the same maximum shunt voltage amplitude, like in a back-to-back converter, can be produced by the nine-switch converter. This maximum is however arrived at a reduced max-imum modulation ratio of $0.95 \times 1.15$, instead of 1.15 with triplen offset considered. The scenario would somehow be im-proved slightly, if an ideal grid is considered instead, in which case, $h_{2}$ is set to zero, as explained in an earlier paragraph. No increase in dc-link voltage is then needed, and the maximum shunt voltage amplitude can be produced at a modulation ratio of 1.15. Replacing of "series-shunt" converter by the nine-switch converter is, therefore, an acceptable option with its saving of three semiconductor switches viewed here as more profound, since they represent heavily underutilized switches found in the back-to-back converter for series compensation purposes.

Yet another issue to address, before the nine-switch converter can be confirmed as a favorable topology for the "series-shunt" power conditioner, is to study its compensating ability under voltage sag condition. For that purpose, the PCC voltage in Fig. 1(b) is assumed to dip by some amount, which would then subject the higher shunt terminal of the nine-switch converter to a reduced voltage level. In contrast, the lower series terminal must respond immediately by injecting a sizable series voltage keep the load voltage close to its pre-fault value. Updating this sag operating scenario to the carrier domain then results in the shunt terminal using a reduced reference, and the series terminal widening its reference range to include a sizable fundamental component, regardless of whether $h_{2}$ is initially zero for an ideal grid or taking a small value for a distorted grid. Since both references are now predominantly fundamental with sizable amplitudes, their placement can ended up like the example drawn on the right of Fig. 3 with the same earlier mentioned phase-shift limitation imposed. Fortunately, this limitation will not hinder the operation of the nine-switch conditioner, since large injected series voltage with a demanding phase shift is usually accompanied by a severe sag at the PCC, and hence a much reduced shunt modulating reference. The compressed shunt reference would then free up more carrier space below it for the series reference to vary within, as easily perceived from the example drawn on the right of Fig. 3.

In conclusion, the proposed nine-switch power conditioner can indeed operate well under both normal and sag operating conditions, owing to its auto complementary tuning of shunt and series references within the single common carrier band. Suitability of the nine-switch converter for "series-shunt" re-placement is therefore established without any stringent practical limitations encountered, unlike those existing "shunt-shunt" replacements.

Using (2), the modulation plots obtained in Fig. 4 clearly show the upper reference tied to only the upper dc-rail and lower reference tied to only the lower dc-rail for a continuous duration of $120^{\circ}$ per fundamental cycle. No crossover of references is observed, implying that the basic modulation rule-of-thumb of the nine-switch converter is not breached, and the $120^{\circ}$-discontinuous scheme is indeed a suitable scheme for reducing its commutation count by $33 \%$. Lower commutation count would then lead to lower switching losses, whose values depend on the current amplitudes and phases at the two terminals per phase, like all other converters modulated discontinuously. Before proceeding on to Sections IV-A and IV-B on higher level control, it is fair to comment here that a similar modulation scheme can be found in [21], whose derivation is oriented more toward the space vector approach. Surely, the space vec-tor domain can be insightful, but it also needlessly complicates the modulation process, and does not bring out the clamping patterns between the two references per phase as clearly as the carrier-based approach.

The latter is therefore preferred, and has independently been used by the authors to develop the $120^{\circ}$ discontinuous scheme, first presented in [22].

\section{B. Series Control Principles}

The series terminals of the nine-switch UPQC are given two control functions that can raise the quality of power supplied to the load under normal and sag operating conditions. For the former, the series terminals of the conditioner are tasked to compensate for any harmonic distortions that might have originated at the PCC.

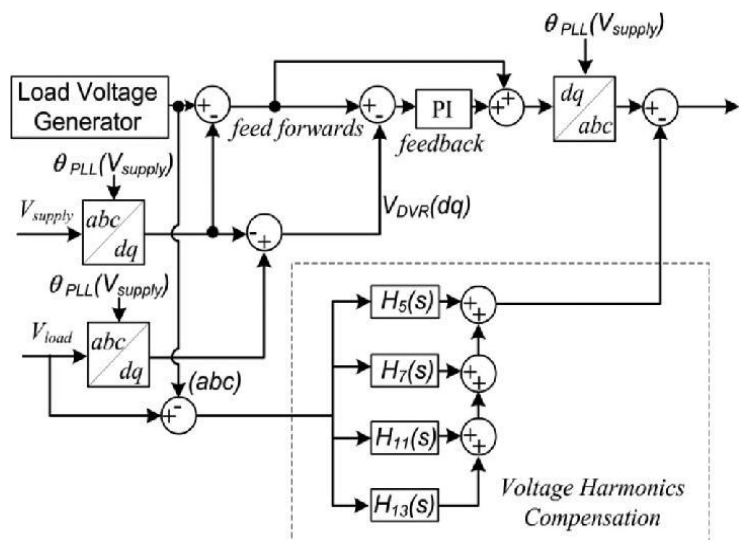

Fig. 5. Series control block representation. 
Where necessary, they should also help to regulate the load voltage to compensate for any slight fundamental voltage variation. This second functionality is, however, more relevant under to keep the load voltage nearly constant. The overall control block representation realized is shown in Fig. 5, where the subsystem responsible for voltage harmonic compensation is distinctly identified within the rectangular enclosure.

In contrast, if realized in the synchronous frame, two control paths per harmonic would generally be needed for processing positive- and negative-sequence components separately. Depending on the number of harmonics considered, such separate paths might end up overstressing the control circuit or microcontroller unnecessarily. To avoid these unwarranted complications, implementation in the stationary frame is therefore preferred, and would in fact suit the carrier-based modulation scheme presented in Section III-A better.

\section{Shunt Control Principles}

As per previous power conditioners, the shunt terminals of the nine-switch power conditioner are programmed to compensate for downstream load current harmonics, reactive power, and to balance its shared dc-link capacitive voltage. To realize these control objectives, an appropriate control scheme is drawn in Fig. 7, where the measured load current is first fed through a high-pass filter in the synchronous frame. The filter blocks fundamental d-axis active component, and passes forward the harmonics and $\mathrm{q}$-axis reactive component for further processing. In parallel, a PI regulator is also added to act on the dc-link voltage error, forcing it to zero by generating a small $\mathrm{d}$ axis control reference for compensating losses, and hence maintaining the dc-link voltage constant. The sum of outputs from the filter and PI regulator then forms the control reference for the measured shunt current to track. Upon tracked properly, the source current would be sinusoidal, and the load harmonics and reactive power would be solely taken care of by the proposed power conditioner.

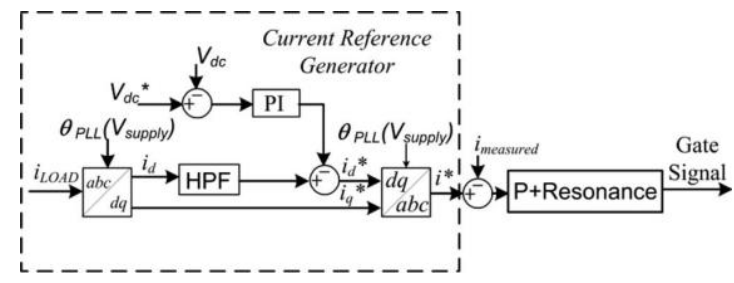

Fig. 7. Shunt control block representation.

\section{SIMULATION RESULTS}

To validate its performance, a nine-switch power conditioner was implemented in the MATLAB, and controlled using a proposed controller.

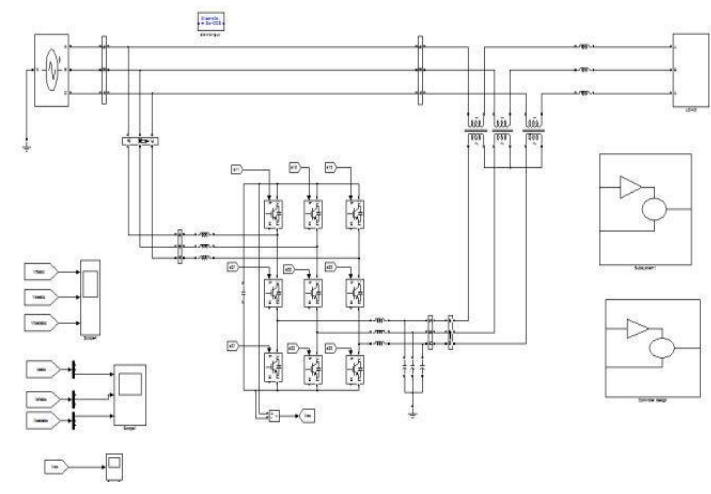

Fig. 8. Simulink Model of Fuzzy based Nine Switch Power Conditioner.

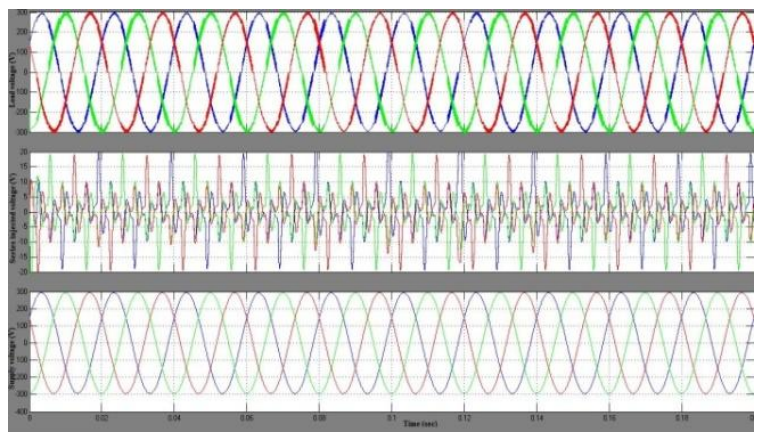

Fig. 10. Source, shunt injection and load currents captured during normal power conditioning mode.

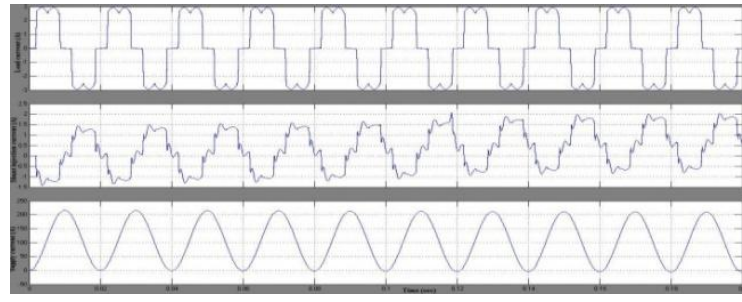

Fig 11. Grid, shunt injection, and load currents during (a) normal-to-sag and (b) sag-to-normal transitions.

\section{CONCLUSION}

This paper evolves Fuzzy based nine switch converter is simulated using MAT LAB/SIMULINK. It effectively reduces the current and voltage harmonics. The nineswitch converter is more suitable for replacing back- toback converter in "series- shunt" systems. As a further performance booster, a modified space vector modulation and 120 degree modulation scheme is presented for reducing the overall commutation count by $33 \%$. It is also compensated for voltage sags, total harmonic distortion with proper series and shunt controls. Since the number of switches required is less compared to conventional converter, the switching losses are less.

\section{REFERENCES}

[1] D. L. Ashcroft, "The static power converter committee-Some perspec-tives," IEEE Trans. Ind. Applicat., vol. IA-21, no. 5, pp. 1097-1098, Sep. 1985.

[2] B. Han, B. Bae, H. Kim, and S. Baek, "Combined operation of unified power-quality conditioner with distributed generation," IEEE Trans. Power Delivery, vol. 21, no. 1, pp. 330-338, Jan. 2006.

[3] H. Johal and D. Divan, "Design considerations for series-connected dis-tributed FACTS converters," IEEE Trans. Ind. Applicat., vol. 43, no. 6, 
[4] T. L. Lee, J. C. Li, and P. T. Cheng, "Discrete frequency tuning active filter for power system harmonics," IEEE Trans. Power Electron., vol. 24, no. 5, 1209-1217, May 2009.

[5] V. Khadkikar and A. Chandra, "A new control philosophy for a uni-fied power quality conditioner (UPQC) to coordinate loadreactive power demand between shunt and series inverters," IEEE Trans. Power Del., vol. 23, no. 4, pp. 2522-2534, Oct. 2008.

[6] Y., W. Li, D. M. Vilathgamuwa, and P. C. Loh, “A grid-interfacing power quality compensator for three-phase three-wire microgrid applications," IEEE Trans. Power Electron., vol. 21, no. 4, pp. 1021-1031, Jul. 2006.

[7] J. W. Kolar, F. Schafmeister, S. D. Round, and H. Ertl, "Novel three-phase ac-ac sparse matrix converters," IEEE Trans. Power Electron., vol. 22, no. 5, pp. 1649-1661, Sep. 2007.

[8] P. C. Loh, F. Blaabjerg, F. Gao, A. Baby, and D. A. C. Tan, "Pulsewidth modulation of neutral-point-clamped indirect matrix converter," IEEE Trans. Ind. Applicat., vol. 44, no. 6, pp. 18051814, Nov./Dec. 2008.

[9] F. Blaabjerg, S. Freysson, H. H. Hansen, and S. Hansen, "A new op-timized space-vector modulation strategy for a componentminimized voltage source inverter," IEEE Trans. Power Electron., vol. 12, no. 4, 704-714, Jul. 1997.

[10] E. Ledezma, B. McGrath, A. Munoz, and T. A. Lipo, "Dual acdrive system with a reduced switch count," IEEE Trans. Ind. Applicat., vol. 37, no. 5, pp. 1325-1333, Sep./Oct. 2001.

[11] M. Jones, S. N. Vukosavic, D. Dujic, E. Levi, and P. Wright, "Fiveleg inverter PWM technique for reduced switch count two-motor constant power applications," IET Proc. Electric Power Applicat., vol. 2, no. 5, 275-287, Sep. 2008.

[12] C. Liu, B. Wu, N. R. Zargari, D. Xu, and J. Wang, "A novel threephase three-leg ac/ac converter using nine IGBTs," IEEE Trans. Power Electron., vol. 24, no. 5, pp. 1151-1160, May 2009.

[13] T. Kominami and Y. Fujimoto, "A novel three-phase inverter for indepen-dent control of two three-phase loads," in Proc. IEEE-Ind. Applicat. Soc. (IAS)s, 2007, pp. 2346-2350.

[14] T. Kominami and Y. Fujimoto, "Inverter with reduced switchingdevice count for independent ac motor control," in Proc. IEEEIECON, 2007, 1559-1564.

[15] C. Liu, B. Wu, N. R. Zargari, and D. Xu, “A novel nine-switch PWM inverter topology for three-phase UPS applications," in Proc. IEEEEveryday Practical Electron. (EPE), 2007, pp. 1-10.

[15] S. M. Dehghan, M. Mohamadian, and A. Yazdian, "Hybrid electric vehicle based on bidirectional Z-source nine-switch inverter," IEEE Trans. Veh. Technol., vol. 59, no. 6, pp. 2641-2653, Jul. 2010.

[16] M. , J. Newman, D. G. Holmes, J. G. Nielsen, and F. Blaabjerg, “A dynamic voltage restorer (DVR) with selective harmonic compensation at medium voltage level," IEEE Trans. Ind. Applicat., vol. 41, no. 6, pp. 1744-1753, Nov./Dec. 2005.

[17] M. J. Newman and D. G. Holmes, "A universal custom power conditioner (UCPC) with selective harmonic voltage compensation," in Proc. IEEE-IECON, 2002, pp. 1261-1266.

[18] Y. Li, D. M. Vilathgamuwa, and P. C. Loh, "Microgrid power quality en-hancement using a three-phase four-wire grid-interfacing compensator," IEEE Trans. Ind. Applicat., vol. 41, no. 6, pp. 17071719, Nov./Dec. 2005.

[19] O. Ojo, "The generalized discontinuous PWM scheme for threephase voltage source inverters," IEEE Trans. Ind. Electron., vol. 51, no. 6, 1280-1289, Dec. 2004.

[20] S. M. D. Dehnavi, M. Mohamadian, A. Yazdian, and F. Ashrafzadeh, "Space vectors modulation for nine-switch converters," IEEE Trans. Power Electron., vol. 25, no. 6, pp. 14881496, Jun. 2010.F. Gao, L. Zhang, D. Li, P. , C. Loh, Y. Tang, and H. Gao, "Optimal pulsewidth modulation of nine-switch converter," IEEE Trans. Power Electron., vol. 25, no. 9, pp. 2331-2343, Sep. 2010.

[21] D. N. Zmood, D. G. Holmes, and G. H. Bode, "Frequency-domain analysis of three-phase linear current regulators," IEEE Trans. Ind. Appl., vol. 37, no. 2, pp. 601-610, Mar./Apr. 2001. 1190

[22] P. Mattavelli, "Closed-loop selective harmonic compensation for active filters," IEEE Trans. Ind. Appl., vol. 37, no. 1, pp. 81-89, Jan./Feb. 2001.

[23] R. Teodorescu, F. Blaabjerg, M. Liserre, and P. C. Loh, "Proportional-resonant controllers and filters for grid-connected voltage-source convert-ers," IEE Proc. Electric Power Applicat., vol. 153, no. 5, pp. 750-762, Sep. 2006.

[24] D. N. Zmood and D. G. Holmes, "Stationary frame current regulation of PWM inverters with zero steady-state error," IEEE Trans. Power Electron., vol. 18, no. 3, pp. 814-822, May 2003. 